Supplement of Geosci. Model Dev., 9, 1827-1851, 2016

https://doi.org/10.5194/gmd-9-1827-2016-supplement

(C) Author(s) 2016. This work is distributed under

the Creative Commons Attribution 3.0 License.

(c) (i)

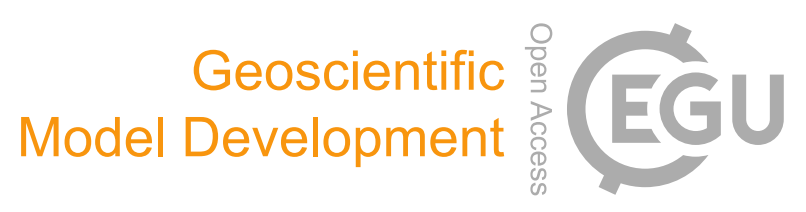

Supplement of

\title{
Inconsistent strategies to spin up models in CMIP5: implications for ocean biogeochemical model performance assessment
}

Roland Séférian et al.

Correspondence to: Roland Séférian (rseferian.cnrm@gmail.com)

The copyright of individual parts of the supplement might differ from the CC BY 3.0 License. 


\section{- Supplementary Figures -}

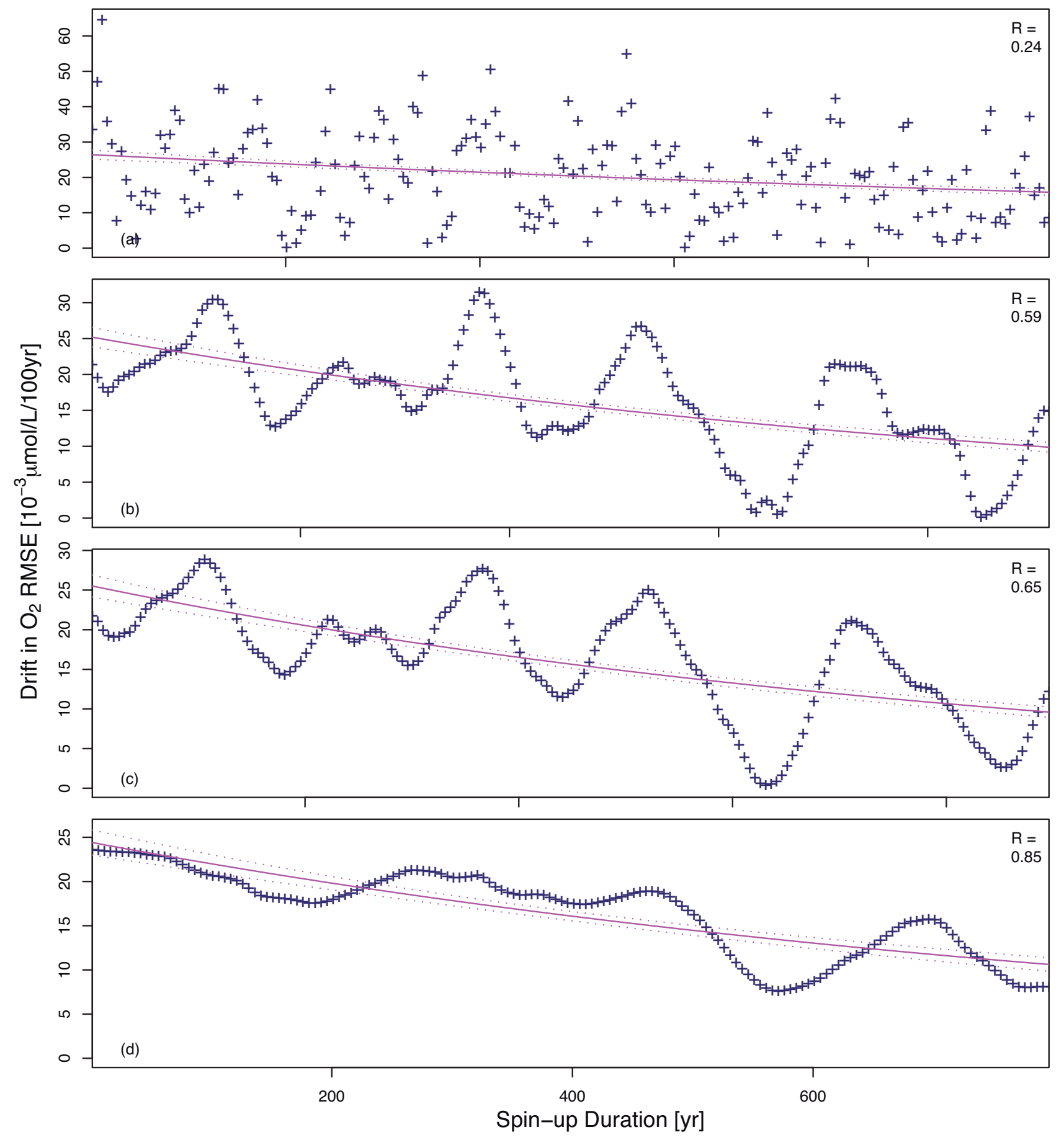

Figure S 1: Temporal evolution of the drift in $\mathrm{O}_{2}$ root-mean squared error (RMSE) at $2000 \mathrm{~m}$ over the 1000-year-long CMIP5 piControl simulation of IPSL-CM5A-LR. Drift in $\mathrm{O}_{2}$ RMSE is computed from time segments of (a) 20, (b) 50, (c) 80, and (d) 100 years distributed evenly every 5 years from the beginning until the end of the piControl simulation. The best-fit linear regressions between drifts in $\mathrm{O}_{2}$ RMSE and simulation duration are indicated in solid magenta lines; their $90 \%$ confidence intervals are given by thin dashed envelope. 

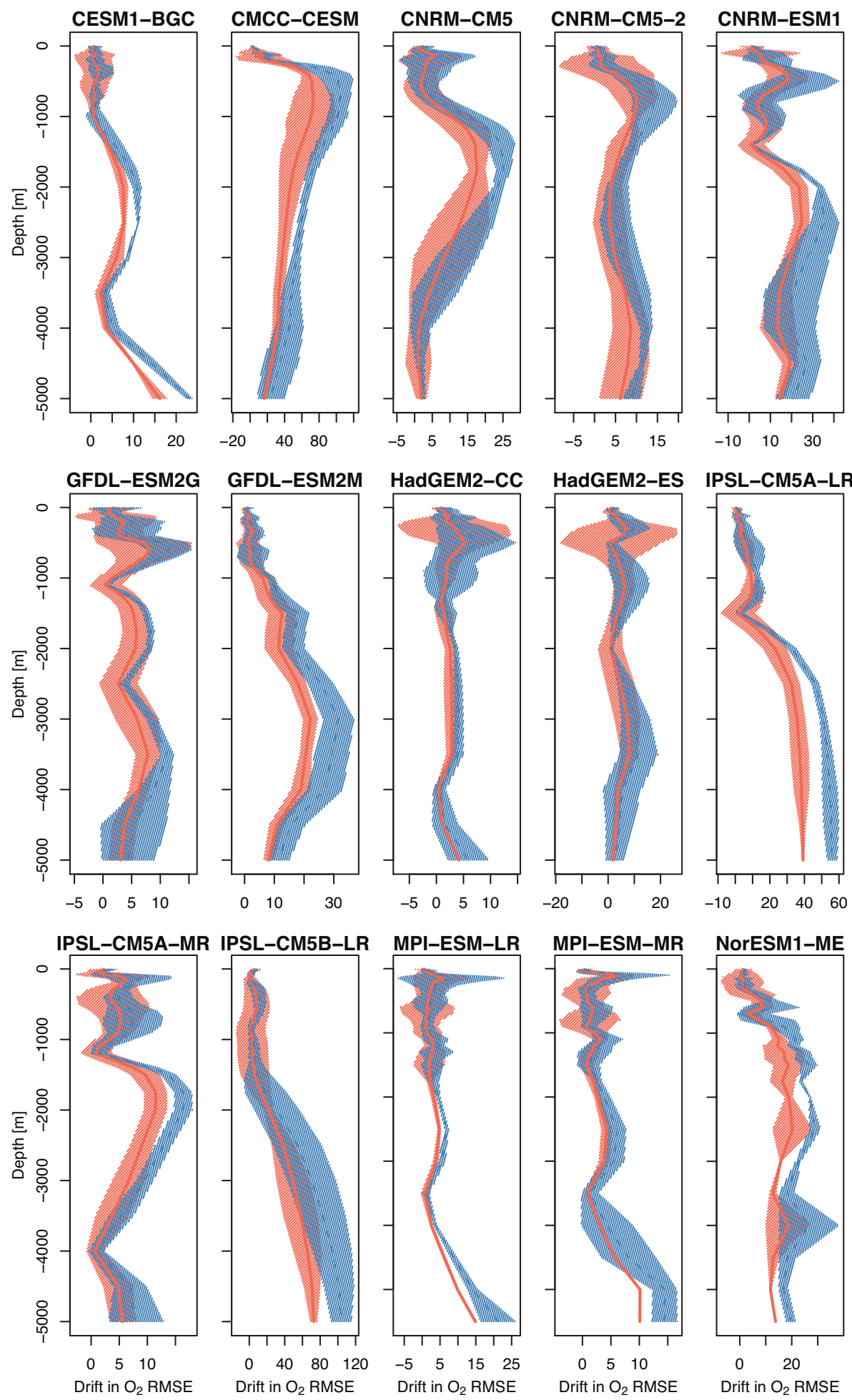

Figure S 2: Vertical profiles of the globally averaged drift in $\mathrm{O}_{2}$ root-mean squared error (in $10^{-3} \mu \mathrm{mol}$ $\mathrm{L}^{-1} \mathrm{kyr}^{-1}$ ) from the 15 CMIP5 Earth system models used in this study. Two ways to determine the globally averaged drift are presented in this Figure: vertical profiles determined from globally averaged $\mathrm{O}_{2}$ RMSE are indicated in blue while those computed from the globally averaged 3-dimensionnal drift (i.e., estimated from 3-dimensionnal $\mathrm{O}_{2}$ RMSE over domains where the drift in $\mathrm{O}_{2}$ RMSE fits the simple drift model) are given in red. Solid lines represent the mean vertical profile of the drift in $\mathrm{O}_{2}$ RMSE; the $90 \%$ confidence interval around the mean profile is represented with hatching patterns. 


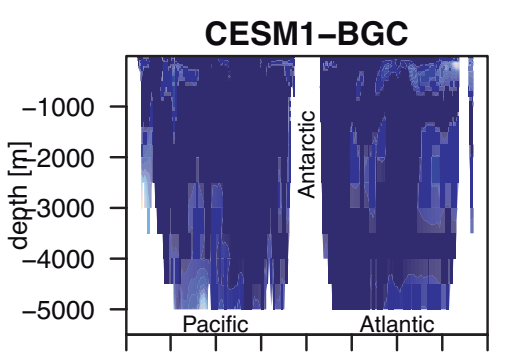

CNRM-CM5-2

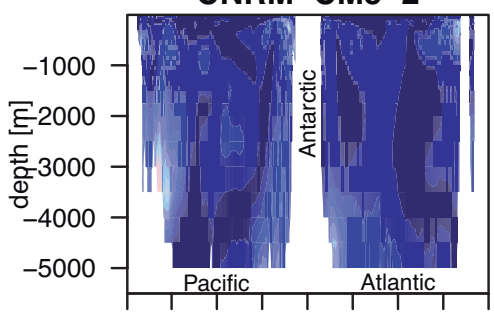

GFDL-ESM2M

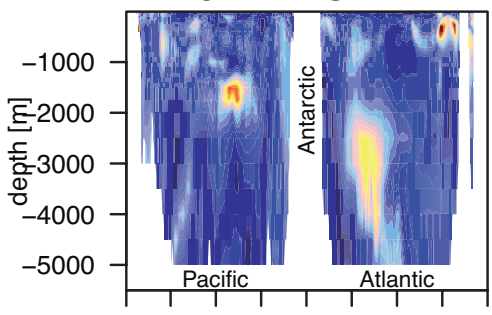

IPSL-CM5A-LR

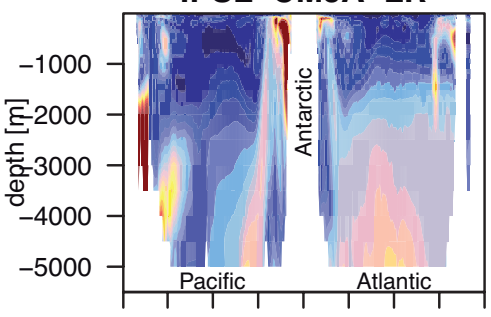

MPI-ESM-LR

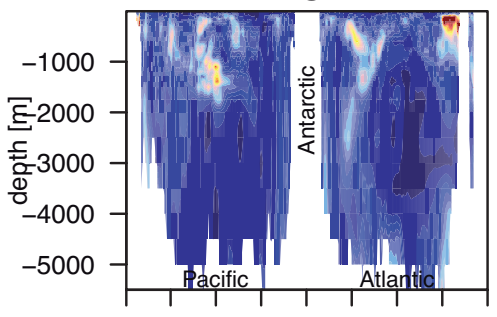

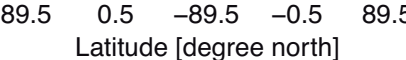

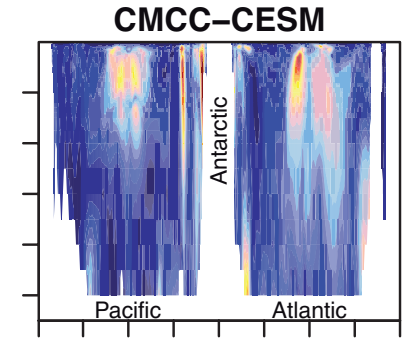

CNRM-ESM1

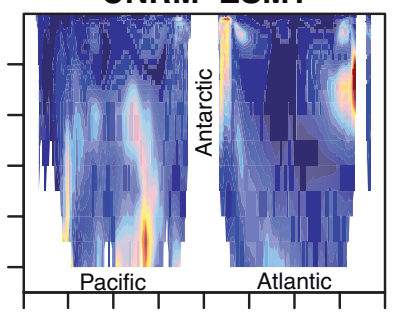

HadGEM2-CC

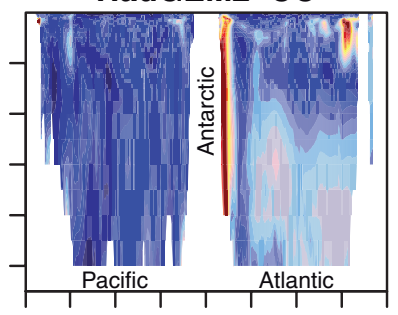

IPSL-CM5A-MR

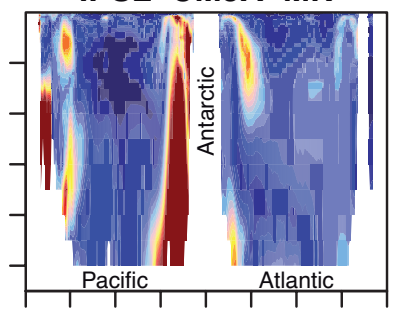

MPI-ESM-MR

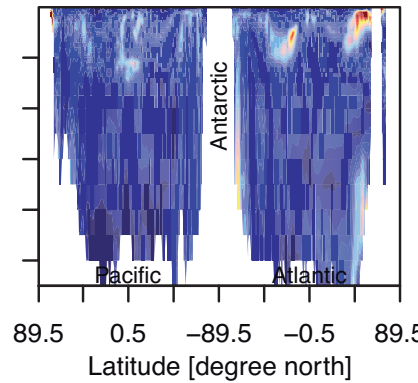

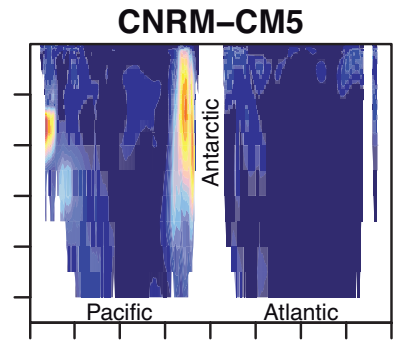

GFDL-ESM2G

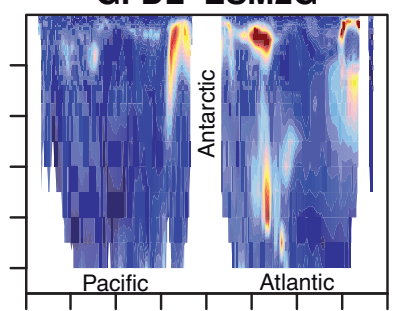

HadGEM2-ES

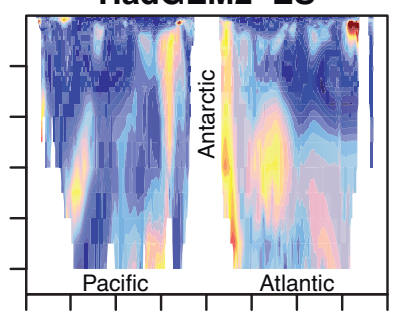

IPSL-CM5B-LR

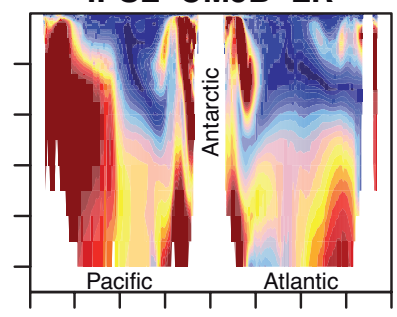

NorESM1-ME

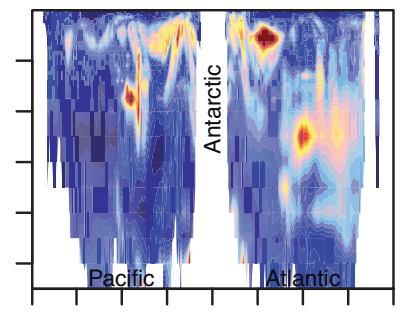

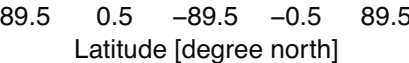

Figure S 3: Vertical structures of the basin-scale drift in $\mathrm{O}_{2}$ root-mean squared error (in $10^{-3} \mu \mathrm{mol}$ $\mathrm{L}^{-1} \mathrm{kyr}^{-1}$ ) from the 15 CMIP5 Earth system models used in this study. Basin-scale drift in $\mathrm{O}_{2}$ RMSE has been computed from 3-dimensionnal drift averaged over Atlantic and Pacific oceans (i.e., estimated from 3-dimensionnal $\mathrm{O}_{2}$ RMSE over domains where the drift in $\mathrm{O}_{2}$ RMSE fits the simple drift model). 